\title{
ULTRA FINE GRAIN/ULTRA LOW CARBON 718
}

\author{
T. Banik, P. W. Keefe, G. E. Maurer and L. Petzold \\ Special Metals Corporation \\ Middle Settlement Road \\ New Hartford, NY 13413
}

\begin{abstract}
An ultra low carbon alloy 718 composition has been investiqated in combination with ultra fine grain processing to improve the low cycle fatigue capabilities of turbine shafts where high cyclic loading and moderate temperature exposures are encountered. Through significant reductions in the carbon level, the presence of carbide and carbo-nitride stringers is reduced. Ultra-fine grain proccssing tcchniques which utilize the secondary phase, delta, to pin grain boundaries provide a microstructure conducive to improved fatigue capabilities.
\end{abstract}

\section{Introduction}

Alloy 718 has become the industry standard for applications where high strength and tomperaturc rosistanco up to $1100^{\circ} \mathrm{F}\left(593^{\circ} \mathrm{C}\right)$ is roquired. Since development in 1959 (1), incremental adjustments in composition, melting, conversion, forging and heat treatment have been made to extend the alloys capability. One such processing step occurred in 1972 when Brown, Boettner and Ruckle (2) of Pratt and Whitney developed the mini-grain process which utilizes the fundamental metallurgical principals of precipitation and deformation to uniformly refine the microstructure.

The original process consisted of precipitating delta phase in cast ingots prior to extrusion. By extruding below the delta solvus, the precipitate was utilized to pin the grain boundaries during deformation and limit the grain size to the inter precipitate spacing. During extrusion, the needle-like delta was effectively broken-up, spheriodized, and dispersed such that traditional problems associated with planer precipitates relative to notch sensitivity, rupture and low cycle fatigue were avoided.

Compositional modifications were significantly slower to evolve. Limitations in trace and tramp element detection may have contributed to the slow evolution of compositional change. Financial concerns may have been, as they are today, a major hinderance to compositional changes. Carbon is one such composilional change caught between early compositional control difficulties and present market driven constraints.

Superalloys 718, 625 and Various Derivatives Edited by Edward A. Loria

The Minerals, Metals \& Materials Society, 1991 
The effect of ultra low carbon compositions was evaluated in 1968 (3) on a series of laboratory heats of multiple superalloys. Ultra low carbon contents were associated with poor rupture life and ductility. More recent evaluations (4) indicated significant reductions in carbide stringers can be achieved in alloy 718 without the previous experienced rupture sensitivities. However, market driven constraints, namely, revert material from machining chips expired components and multiple other after market scrap sources now limit application of ultra low carbon compositions.

Present turbine engines are fatigue limited machines, where fatigue limiting is defined as the time for a crack to nucleate and propagate to a critical size such that the component under study cannot continue to operate to the level of confidence when it was originally put in service. Turbine shafts are one such component where high temperatures from $400^{\circ} \mathrm{F}$ to $800^{\circ}$ or $900^{\circ} \mathrm{F}\left(204^{\circ} \mathrm{C}\right.$ to $427^{\circ}$ or $482^{\circ} \mathrm{C}$ ) are encountered under conditions of rotational, tangential and longitudinal stresses. Such components are designed to alleviate failure at fatigue limiting anomalies, be it a mechanical anomaly such as a notch or metallurgical anomaly such as a coarse grain, melt variation, stringer or inclusion.

Through the combination of ultra fine grain processing or mini-grain processing and low carbon compositions, the material scientist may now be able to address two of the concerns of the turbine shaft design engineer.

\section{Experimental Procedure}

Primary and secondary melting operations were performed in accordance with standard practices established at Special Metals for Alloy 718 . Initial conversion studies were performed on subscale samples using a programed matrix of temperature and roll reduction. Subsequently full scale evaluations were performed to evaluate chemistry and mechanical processing in accordance with the matrix presented in Figure 1 as reported below.

\section{Composition}

Melting operations consisted of vacuum induction melting followed by vacuum arc remelting to 20" DIA. ingots. One full scale heat of standard grade Alloy 718 was melted as a control and a second heat of ultra low carbon Alloy 718 was melted for evaluation. The chemical composition of the electrodes are prosented in Table I.

Standard Fine Grain Conversion

Conversion operations for Alloy 718 consist of an initial ingot breakdown from temperatures substantially above the delta solvus temperature to temperatures near the delta precipitation range for fine grain billet. Subsequent rolling operations are scheduled to build on the initial microstructural refinement as the billet is converted to the final bar diameter.

\section{Ultra Fine Grain Conversion}

Conversion operations for ultra fine grain processing are similar to the standard fine grain processing through the billet stages. Prior to the final press operations, the billet material was heat treated to precipitate the secondary delta phase as coarse needles. The heat treat cycle was developed on samples prior to exposure of the billet as indicated in Figure 2 . 
Table I One Production Heat was Melted to the Baseline Composition

\begin{tabular}{lcccccccccc}
\hline & $\mathrm{C}$ & $\mathrm{Cr}$ & $\mathrm{Nb}$ & $\mathrm{Ti}$ & $\mathrm{Al}$ & $\mathrm{Mo}$ & $\mathrm{Ni}$ & $\mathrm{Mn}$ & $\mathrm{Si}$ & $\mathrm{Fe}$ \\
\hline $\begin{array}{l}\text { Standard } \\
\text { Chemistry }\end{array}$ & .033 & 18.0 & 5.3 & 1.0 & 0.5 & 2.9 & 54.1 & 0.05 & 0.07 & $\mathrm{Bal}$ \\
$\begin{array}{l}\text { Low } \\
\text { Carbon 718 }\end{array}$ & .006 & 18.1 & 5.2 & 1.0 & 0.5 & 3.0 & 54.5 & 0.02 & 0.02 & $\mathrm{Bal}$ \\
\hline
\end{tabular}


After precipitation, the billet is forged to size at temperatures approximately $50^{\circ} \mathrm{F}\left(28^{\circ} \mathrm{C}\right)$ below the delta solvus to retain the precipitate for microstructural refinement and to restrict grain coarsening on reheating between operations. The standard fine grain and ultra fine grain processes are illustrated in Figure 3.

Heat Treatment

Heat treat operations utilize the standard heat treatment for Alloy 718 which provides a balance of high temperature strength and ductilities indicated below:

$$
\begin{array}{ll}
\text { Solution: } & 1775^{\circ} \pm 15^{\circ} \mathrm{F} / 1 \text { hour } / \text { Oil Quench } \\
\text { Precipitation: } & 1350^{\circ} \pm 15^{\circ} \mathrm{F} / 8 \text { hour } / \text { Furnace Cool at } 100^{\circ} \mathrm{F} \\
& \text { per hour to } 1150^{\circ} \pm 15^{\circ} \mathrm{F} / 8 \text { hour } / \text { Air Conl }
\end{array}
$$

Metallographic Evaluations

As-polished metallographic samples revealed a significant reduction in carbide stringers in the low carbon material as indicated in Figure 4. Although the carbon stringer level is low, the as polished samples do reveal the presence of nitride stringers, which although present, are more dispersed.

The additional microstructural refinement obtained with the ultra fine grain process sequence is clearly evident in micrographs from the forged and heat treated samples presented in Figure 5. The standard fine grain process yields a grain size of ASTM 8 as-large-as 6 while ultra fine grain processed material produces a grain size of ASTM 12-14 with substantial quantities of globular delta. Microstructural refinement was similar for both the standard and low carbon compositions.

\section{SEM Analysis}

With the reduced carbon levels, a minor change in the precipitation of secondary phases which develop during solidification is anticipated. Precipitation occurs initially at oxides serving as nucleation sites for the precipitation of nitrides and then carbides as reported previously in standard grades in Alloy 718 (5). As indicated in Figure 6, this precipitation structure is altered with the reduced carbon levels. The distribution of the carbides in the low carbon composition is significantly reduced to a discrete outlining morphology on the columbium nitride particles, however the overall size of typical particles do not appear significantly smaller in size.

Delta distributions are of primary concern relative to mechanical property response. Image analysis of the heat treated samples from the ultra fine grain processed material indicate globular delta in the range of 12-18 area percent as indicated in Figure 7.

\section{Mechanical Property Response}

Longitudinal and transverse mechanical property testing was selectively performed on bar samples after heat treatment. Comparison of transverse tests performed on ultra fine grain processed material revealed a significant improvement in tensile ductility with the reduced carbon composition as noted in Figure 8.

The rupture properties of the low carbon composition were lower then baseline composition. As indicated in Figurc 9, tests performed in the longitudinal direction revealed reductions in both rupture life and ductility. 
It is evident from the electron microscopy evaluations that sufficient carbon is available to form MC carbides during solidification which are subsequently retained during thermomechanical processing. Additional creep testing will be required to better define relationships between rupture and carbon content.

Longitudinal tosts porformed on the standard fine and ultra fine grain material revealed slightly higher strength and significantly higher ductility levels (Figure 10 ) at $1200^{\circ} \mathrm{F}\left(649^{\circ} \mathrm{C}\right)$. The improvements in strength are most likely a result of the finer grain microstructure and the Hall-Petch effect ( 6 ).

\section{Results and Discussion}

Process modifications to obtain defect free materials is a gradual progression. The combination of reduced carbide stringers and uniform fine grain microstructures addresses two major steps in this progression. Unfortunately, the high carbon levels ( 0.03 to 0.04 weight percent) in present revert material will require significant dilutions of virgin materials to bring the carbon levels to a level where potential benefits can be accessed effectively.

Initial evaluations on the fine grain processing of Alloy 718 (7), indicated approximately 17.5 volume percent of globular delta is sufficient to achieve the proper distribution of gamma prime and gamma double prime during aging. With the ultra fine grain process, the solution heat treat cycle can be utilized to control volume fraction of delta present after thermomechanical processing and provide the necessary amount of Columbium in the matrix for subsequent aging.

The high columbium content of Alloy 718 permits the precipitation of delta in buth alloy lean and alloy rich areas of conventionally melted material. The effectiveness of delta to limit grain growth during subsequent conversion operations reduces the process sensitivity and should permit reduced testing as experience is gained on production quantities.

Two areas which may benefit directly with the application of a ultra fine grain conversion practice are melt related defect sensitivity and ultrasonic inspection. With the delta precipitation cycle, more uniform microstructural refinement is achieved. Alloy lean areas, typically associated with the presence of white spots, will have columbium contents of approximately 4-5 weight percent. Even at these levels, sufficient Columbium should be present to permit delta precipitation during ultra fine grain processing. Therefore, alloy lean areas can be refined to some degree better then existing fine grain practices.

From a non-destructive inspection viewpoint, the significantly finer microstructure and uniformity of microstructure should increase ultrasonic inspectability. However, the benefits may not be evident during inspection of the bar or billet material in the unheat treated condition. The large volume fraction of globular delta in the billet or bar may act as reflectors and result in a loss of the ultrasonic signal during inspection.

Alloy additions are possible which may offset the apparent debit in rupture capability identified with the ultra low carbon composition. These additions, however, will be restricted by end user requirements.

The improvements in microstructural uniformity may reduce the amount of metallographic inspection and subsequent costs associated with mill products. More importantly, the combination of low carbon Alloy 718 and ultra fine grain processing provides the designer added confidence on difficult or defect sensitive components. 


\section{Conclusions}

1. Ultra low carbon Alloy 718 can be produced in production scale ingots through careful revert and virgin charges.

2. Ultra line grain processing incorporaling the use of della phase to control grain growth can be utilized effectively in the production of ultra fine grain bar for turbine shaft applications.

3. Substantial improvements in tensile ductility can be achieved with reduced carbon levels.

4. Tensile strength levels are not compromised with low carbon and delta precipitation conversion operations.

5. The presence of carbide stringers is essentially eliminated with carbon levels of 0.006 weight percent in Alloy 718 .

6. The ultra low carbon Alloy 718 composition exhibits a reduction in rupture life and ductility.

\section{References}

1. J.F. Barker, "The Initial Years of Alloy 718 - A GE Perspective", International Conference on the Metallurgy and Applications of Superalloy 718, Pittsburgh, PA, June 1989.

2. E.E. Brown, R.C. Boettner and D.R. Ruckle, "Minigrain Processing of Ni-base Alloys", 2nd International Symposium on Superalloys, Seven Springs, PA., September, 1972.

3. J.M. Moyer, "Extra Low Carbon Alloy 718", 5th International Symposium on Superalloys, Seven Springs, PA., September, 1984.

4. J.P. Stroup and L.A. Pugliese, "How Low-Carbon Affects Superalloys", Metal Progress, 99(2), 1968, pp 96-100.

5. A. Mitchell, "The Present Status of Melting Technology for A1loy 718", Proceedings of the International Symposium on the Metallurgy and Applications of Superalloy 718 sponsored by TMS, Pittsburgh, PA., June, 1989, p. 4.

6. G.H. Deiter, Mechanical Metallurgy, McGraw-Hill Series in Materials Science and Engineering, 1976, p. 195.

7. G.K. Brouse and M.F. Collins, "Effect of Delta Phase in Alloy 718 on Thermal Mechanical Processing and Tensile Ductility", Structure and Deformation of Boundaries, TMS-AIME, Toronto, Canada, October, 1985. 


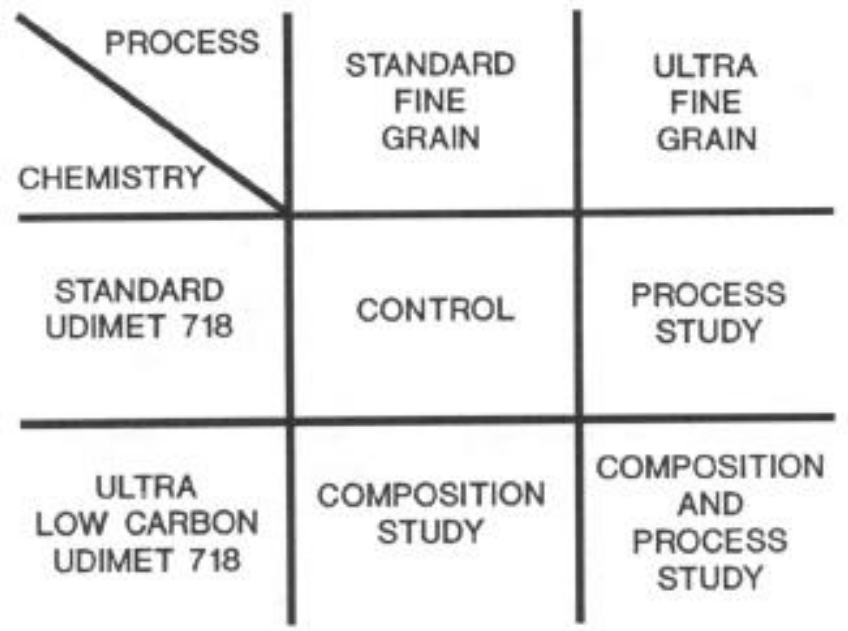

Figure 1 - The Experimental Matrix Included Chemistry and Process Variables

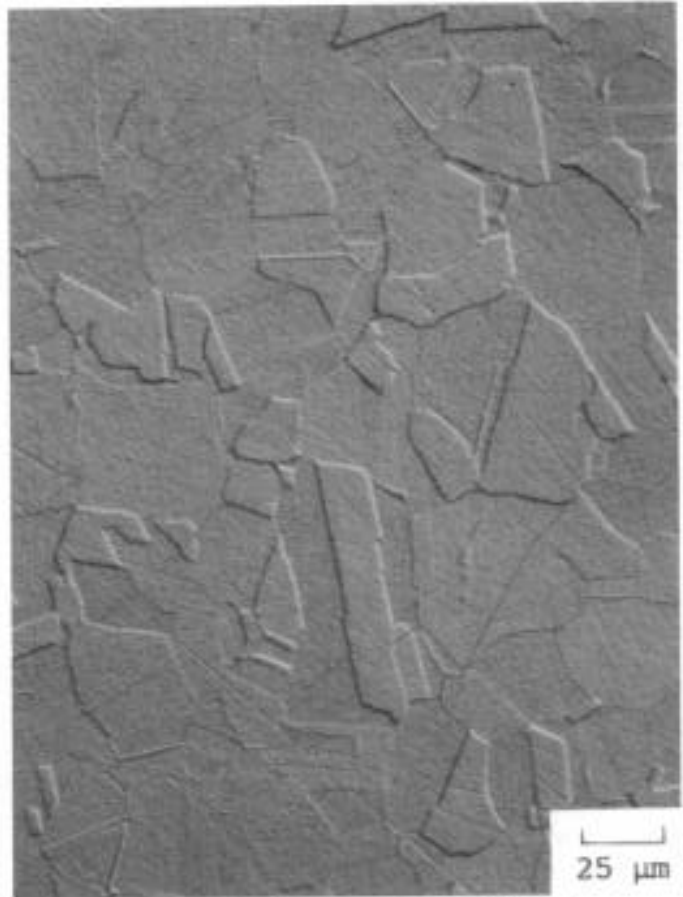

Standard Fine Grain Billet

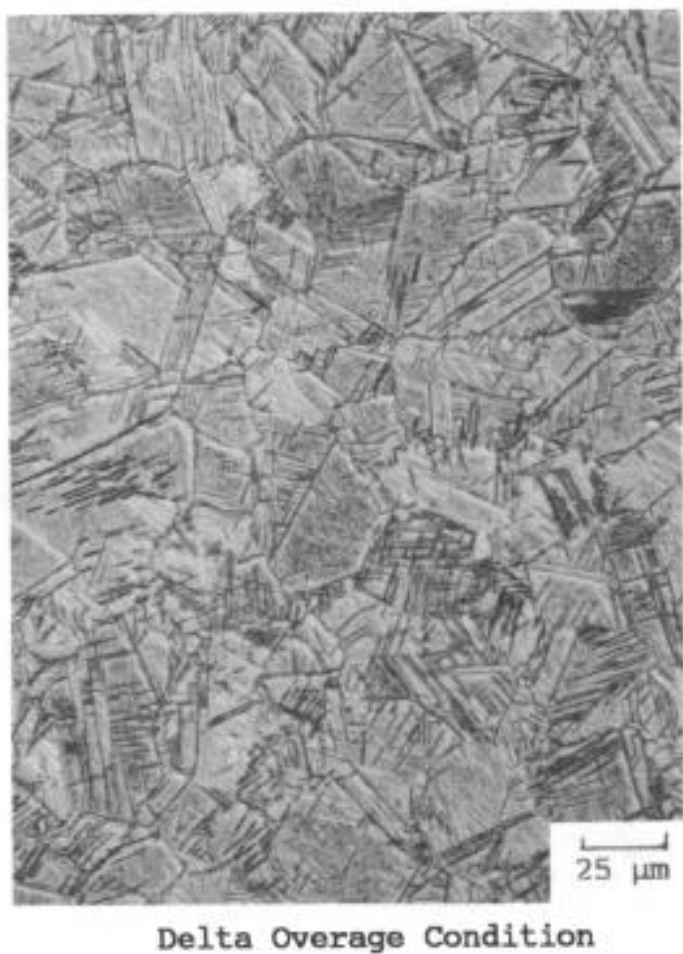

Delta Overage Condition

Figure 2 - Standard Billet Samples Were Utilized to Bstablish Delta Precipitation Parameters 


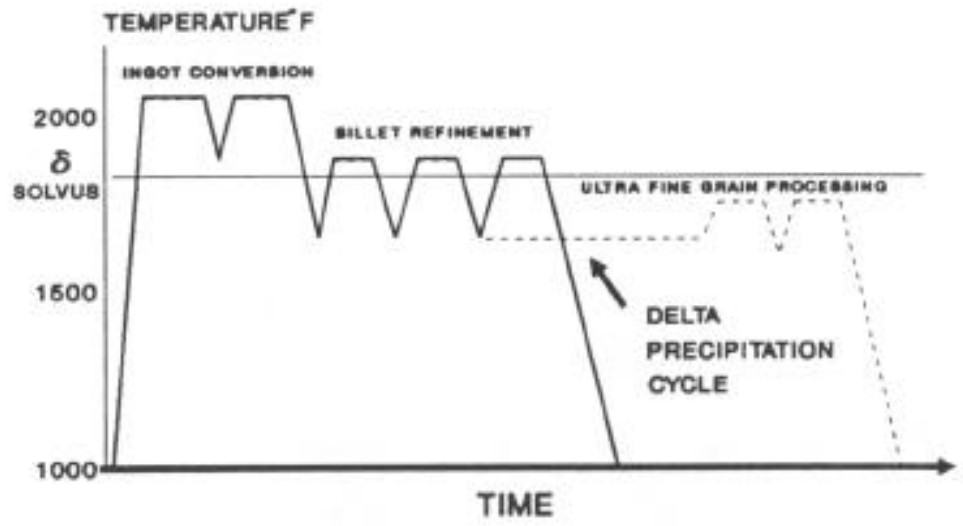

- FINE GRNN …-ULTRA FINE GRNN

Figure 3 - The Delta Solvus Limits U1tra Fine Grain Process Temperature

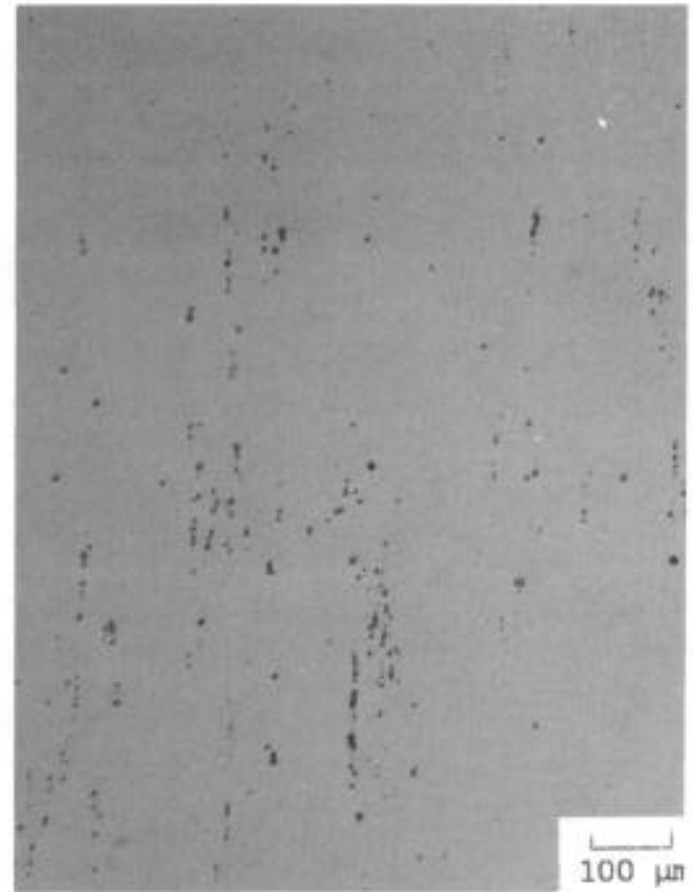

Standard Udimet Alloy 718

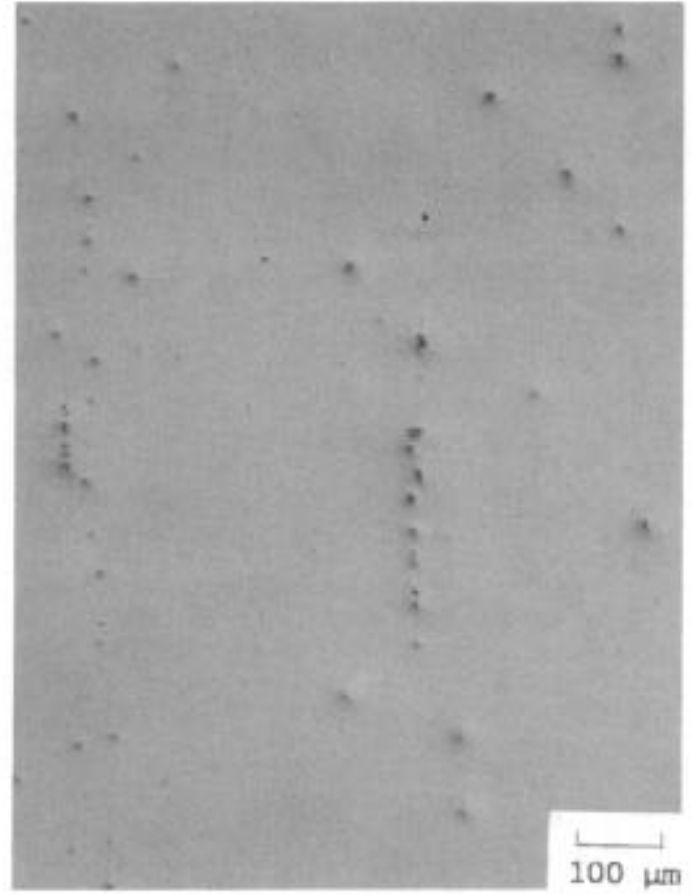

Ultra Low Carbon Udimet Alloy 718

Figure 4 - Carbide Distribution was Significantly Reduced 


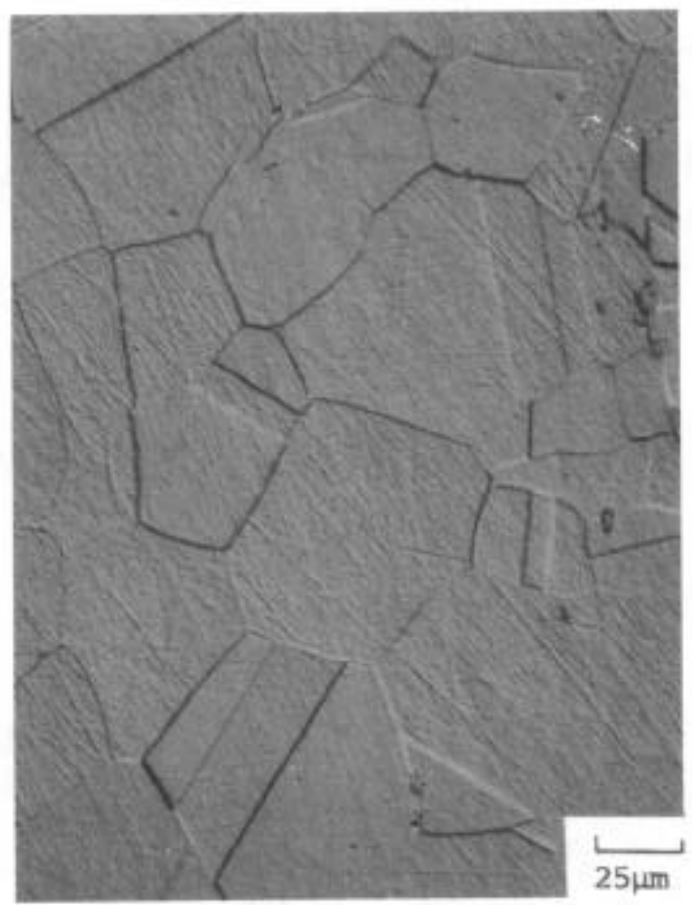

Standard Fine Grain Process

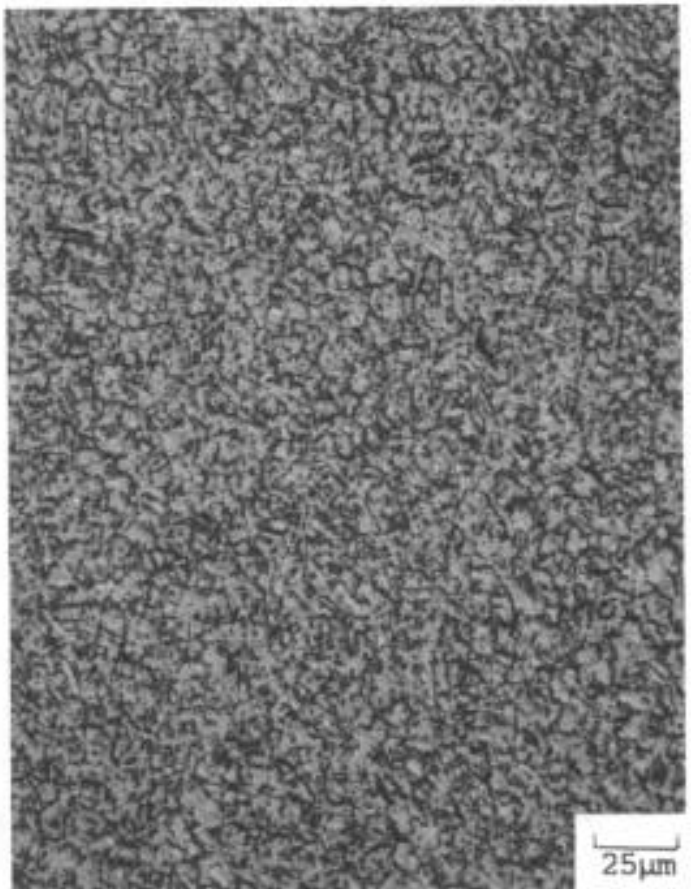

Ultra Fine Grain Process

Figure 5 - Microstructural Refinement is Significantly Improved 


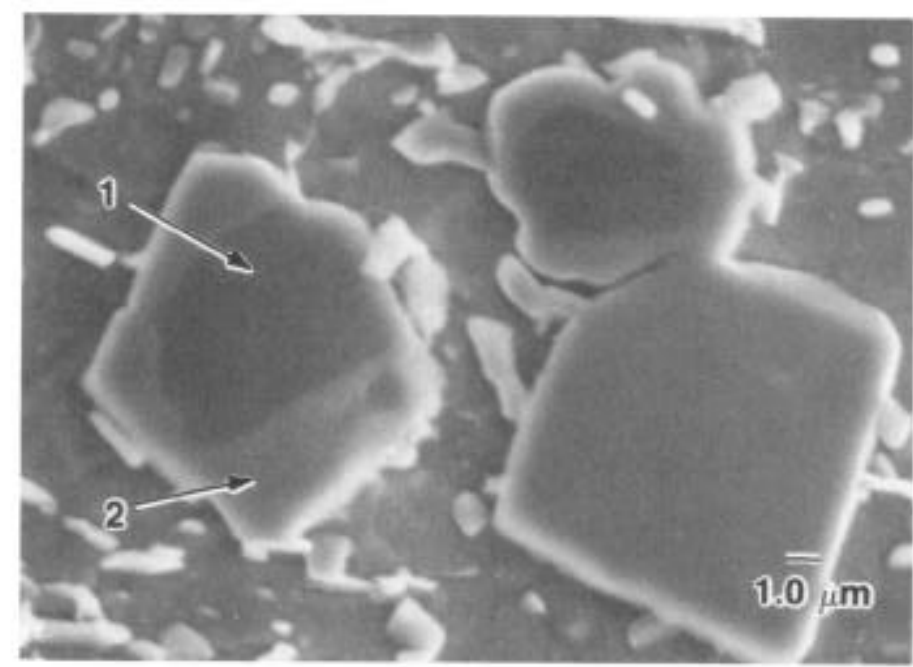

Standard Udimet Alloy 718
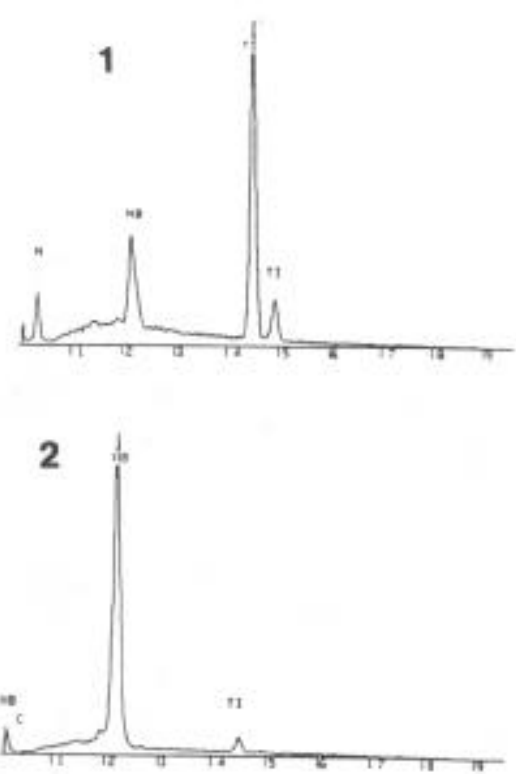
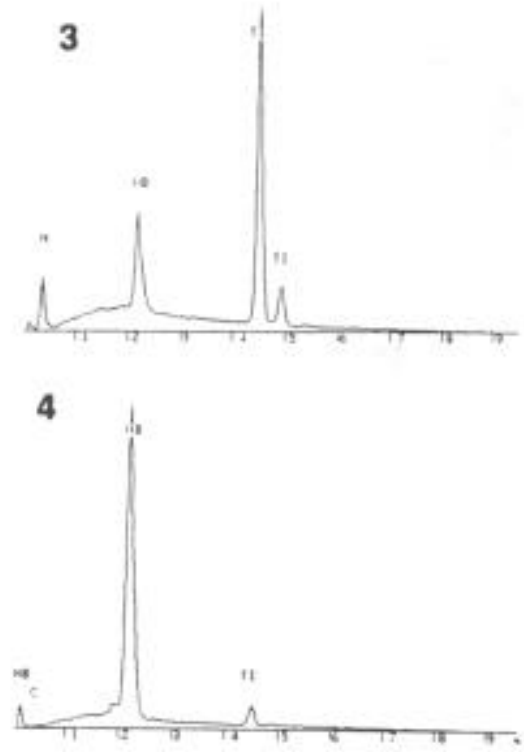

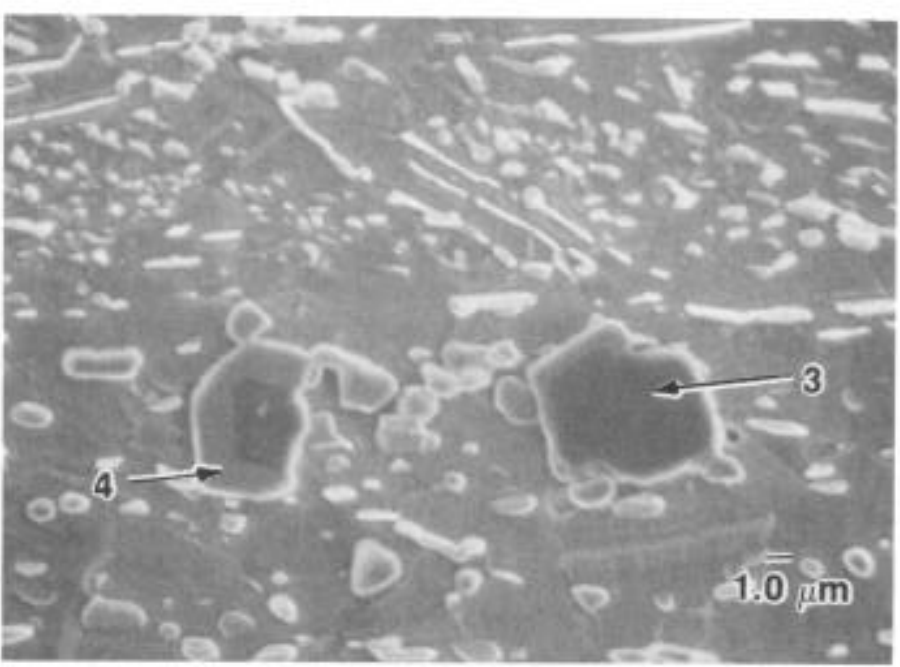

Ultra Low Carbon Udimet Alloy 718

Figure 6 - The Carbide Film on Precipitated Nitrides Was Significantly Less with the Ultra Low Carbon Composition 


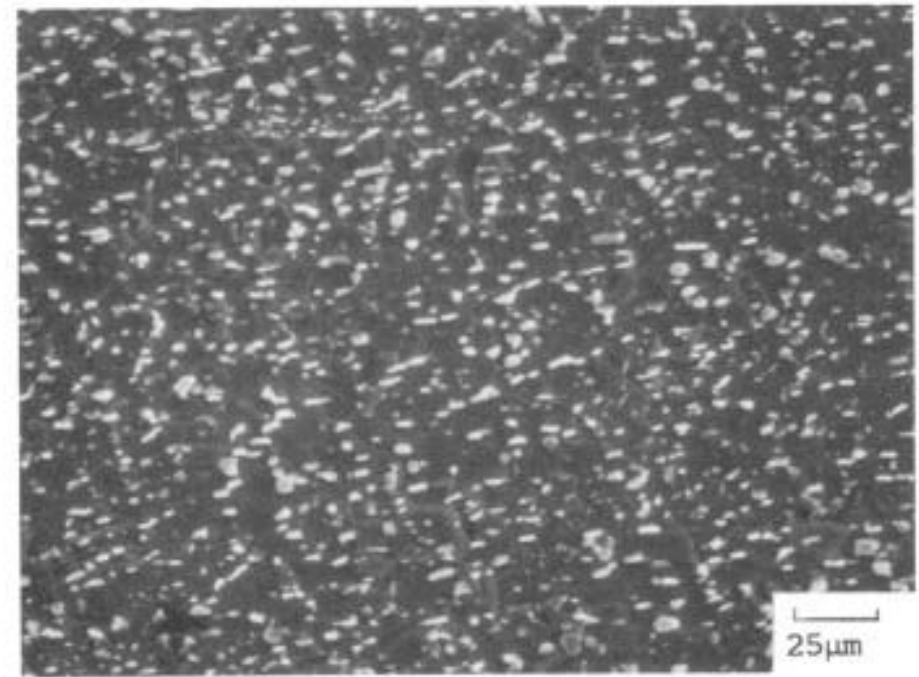

Figure 7 - The Globular Delta Phase Was 12-18 Area Percent*

* By Image Analysis

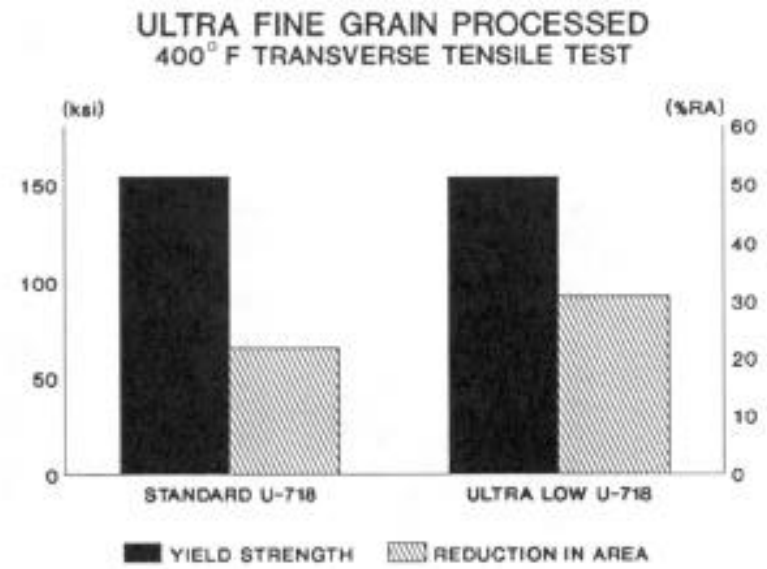

Figure 8 - Transverse Tests Revealed An Improvement in Tensile Ductility 
STANDARD FINE GRAIN PROCESS

$1200^{\circ} \mathrm{F}, 105 \mathrm{KSI}$ LONGITUDINAL RUPTURE TEST

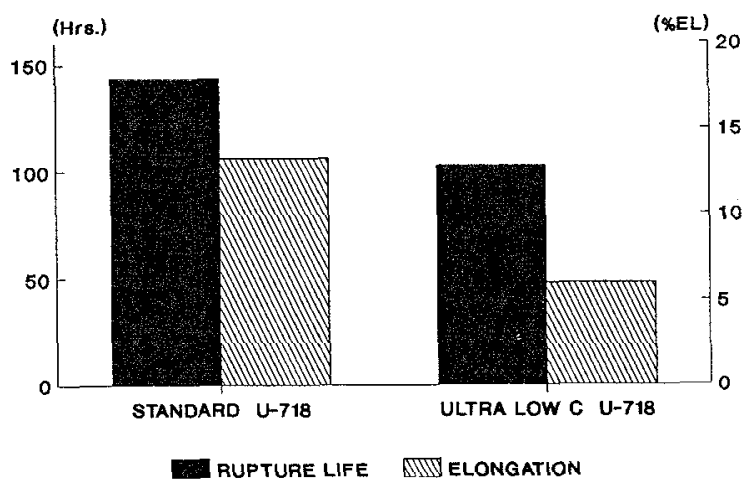

Figure 9 - Reduced Carbon Levels Apparently Reduced Rupture Capability

ULTRA LOW CARBON COMPOSITION $1200^{\circ} \mathrm{F}$ LONGITUDINAL TENSILE TEST

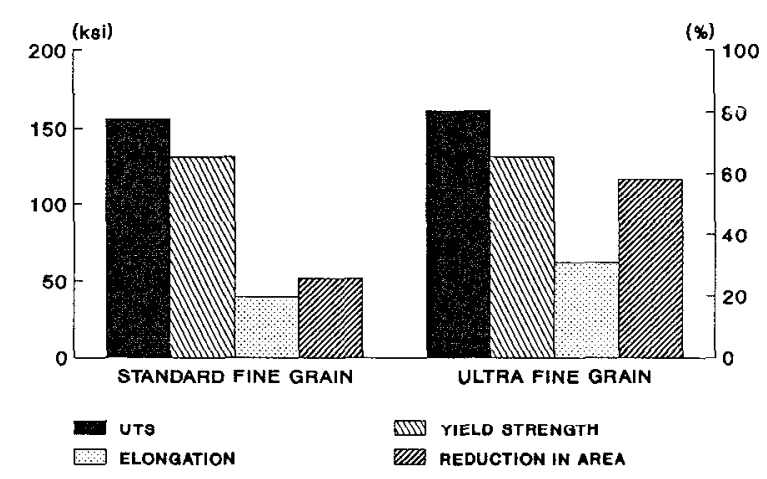

Figure 10 - Longitudinal Tensile Capability For Ultra Fine Grain Material Was Slightly Bettter Than Standard Fine Grain Materials 